\title{
Possible Applications of High Altitude Platform Systems for the Security of South America and South Europe ${ }^{1}$
}

\author{
Attila HORVÁTH ${ }^{2 \oplus}$
}

\begin{abstract}
High Altitude Platform Systems (HAPS) ${ }^{3}$, or pseudo satellites, are atmospheric, specifically, stratospheric Remotely Piloted Aerial Systems (RPAS). ${ }^{4}$ These systems can provide services comparable to outer space satellite systems, however, they can be operated without the need of an orbital launch capability. While their geographical coverage is limited compared to space satellites, they can provide persistent coverage over a given area for a long time, weeks or even months. Pseudo satellites can carry Earth observation or radiocommunication payloads, just like satellites.

In this article I will provide an overview of HAPS capabilities and potential applications, based on an imaginary operational scenario, namely, the reconnaissance support of a law enforcement operation to defend offshore gas facilities from a planned attack by an eco-terrorist group near Venezuela. At the same time, HAPS can support any defence, emergency response or natural resource observation operation.

The complex air-sea operation scenario will be presented using a simulation generated with the AGI Systems ToolKit multi-domain mission simulator software. My article contains maps and pictures of the operation, and the videos will be presented via the https://horvath.space website.
\end{abstract}

Keywords: HAPS, pseudo satellite, stratospheric UAS, High Altitude Platform System, Systems ToolKit

This article, the website and the conference presentation were prepared with the professional support of the Doctoral Student Scholarship Program of the Co-operative Doctoral Program of the Ministry of Innovation and Technology, financed from the National Research, Development and Innovation Fund.

2 Lieutenant Colonel, Hungarian Defence Forces Modernization Institute, e-mail: attila@horvath.space

3 Several sources use the expression High Altitude Platform Station. I prefer, and I am going to use System, since in my opinion, it is not right to separate the aerial vehicle from the whole operational architecture.

$4 \quad$ 'Introduction to Remotely Piloted Aircraft Systems (RPAS)', Skybrary, s. a. 


\section{Introduction}

Information has long been the decisive factor behind most human activities, military, law enforcement, and other security and defence related actions notwithstanding. According to Sun Tzŭ, "what enables the wise sovereign and the good general to strike and conquer, and achieve things beyond the reach of ordinary men, is foreknowledge". ${ }^{5}$ This foreknowledge, information, needs to be collected, transmitted, analysed, and the products and orders disseminated.

Space satellites are widely used for these actions to support operations vital for state functions. But they are not the only one, especially when their drawbacks are also considered.

In this article I will present another tool, usually called High Altitude Platform Systems, which are atmospheric aircraft, but can provide services comparable to space satellites, ${ }^{6}$ and since in some respects they can even be considered superior to them, ${ }^{7}$ but at the same time they need the services of space satellites to operate effectively, they are two important assets to be used in an integrated way, to enhance the operational values of each of them synergistically.

The purpose of this article is to provide a comparative analysis by reviewing the potential services provided by pseudo satellites and contrasting them with the services nowadays provided by, on the one hand, remotely piloted aircraft powered by air-breathing engines, and on the other hand, outer space satellites.

\section{The scenario}

Disclaimer: this scenario is a work of fiction. It is used to give context for the mission analysis and the description of High Altitude Platform Systems and their capabilities.

Law enforcement services of Venezuela intercepted an encrypted text message sent from a suspected operations coordinator of the environmental terrorist organisation " $\mathrm{El}$ Fuego Verde". This organisation has committed numerous attacks against chemical, petrochemical and nuclear facilities, causing severe damage, loss of property and life.

The encryption was partially broken, and part of the message recovered: "[...] Dragon field [...] pipeline [...] explosion.” Analysts of law enforcement services came to the conclusion that the plan of the terrorist organisation was to blow up the Dragon gas field facilities and/or the pipeline connecting Dragon to Hibiscus field facilities, offshore Venezuela and Trinidad and Tobago.

Political decision has been made that deterring the terrorists from the attack is not enough: they need to be caught in the act, captured and taken before the court of law.

5 Quoted from the translation by Lionel Giles, MA, Sun Tzŭ, The Art of War (trans. by Lionel Giles, MA, 1910).

${ }_{6}$ Anggoro K Widiawan and Rahim Tafazolli, 'High Altitude Platform Station (HAPS): A Review of New Infrastructure Development for Future Wireless Communications', Wireless Personal Communications 42 (2007), 387-404.

7 Gunes Karabulut Kurt et al., 'A Vision and Framework for the High Altitude Platform Station (HAPS) Networks of the Future', IEEE Communications Surveys \& Tutorials 23, no 2 (2021). 
Therefore, no sign of prior preparation by law enforcement must be detected by the terrorists, still, constant surveillance of the threat area is necessary. No time window for the attack could be determined.

To interdict the terrorists, law enforcement services asked for the assistance of the Bolivarian Navy of Venezuela. The Commandante General of the Bolivarian Navy designated the patrol vessel GC-21 Guaicamacuto for the operation.

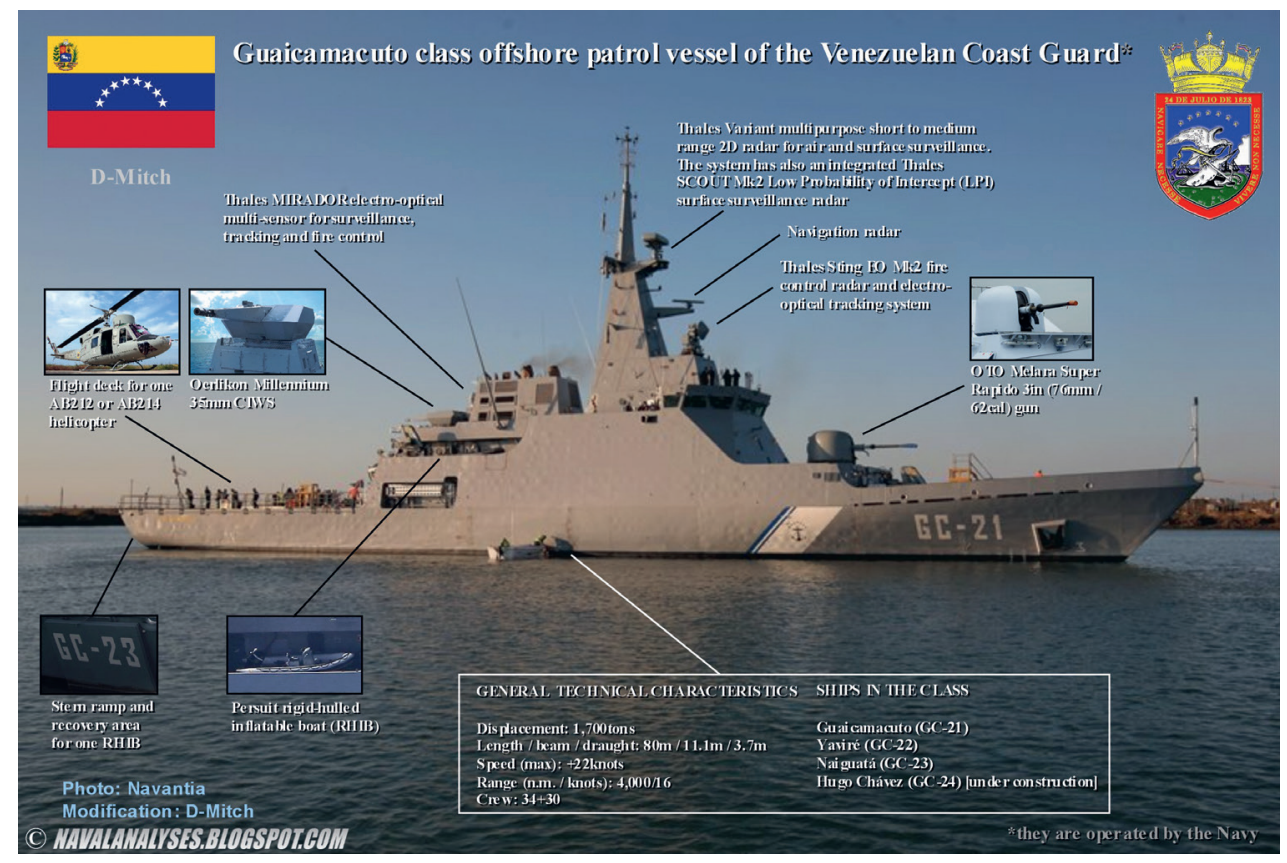

Figure 1: Infographic of the GC-21 Guaicamacuto class offshore patrol vessel ${ }^{8}$

Source: navalanalyses.com.

For the persistent surveillance, an unmanned stratospheric surveillance platform, conducting environmental survey with multispectral day/night electro-optical imaging payload in the Orinoco Delta, was re-tasked to fly toward the threat area.

8 The picture is a composite of the GC-21 and GC-23 Naiguatá; this ship sunk in 2020 after the collision with or ramming of RCGS Resolute during a controversial maritime interdiction operation. 


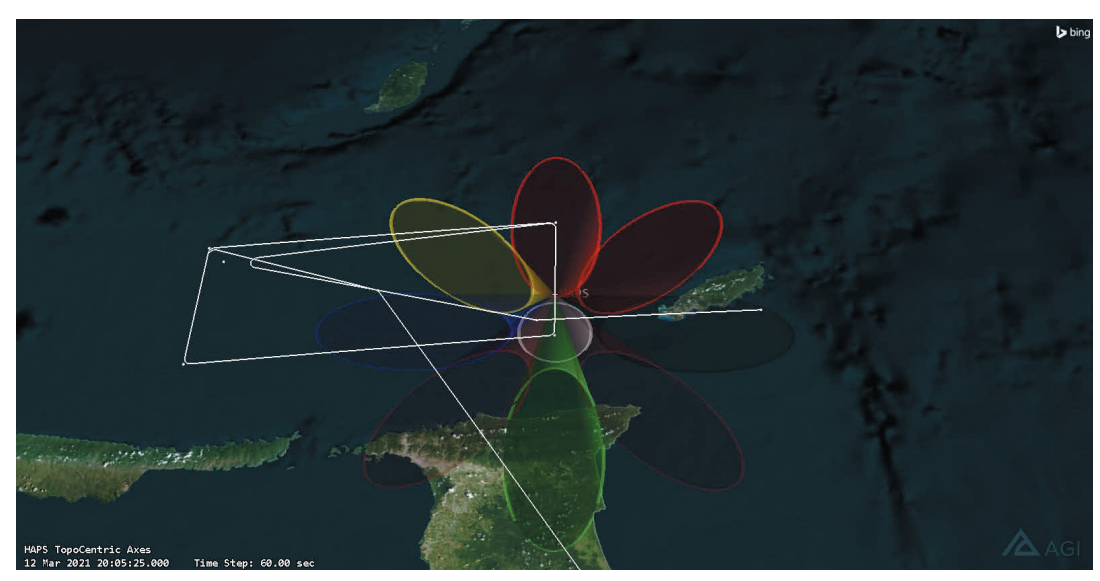

Figure 2: Overview of the patrol area

Note: The HAPS entered from the south, over Trinidad Island, turned portside and started a counterclockwise patrol pattern, finally leaving the area to the east. The route of the HAPS is shown in white. The simulated sensor footprints are shown by the coloured ellipses.

Source: Systems ToolKit simulation by the author.

A patrol pattern was uploaded to the HAPS from the operations centre via satellite, and the aircraft started the continuous scanning of the surface. When an unidentified speedboat, not broadcasting AIS signals, was detected, the GC-21 was alerted. The patrol vessel moved from its hiding area behind Península de Paria, and steamed out to intercept the boat.

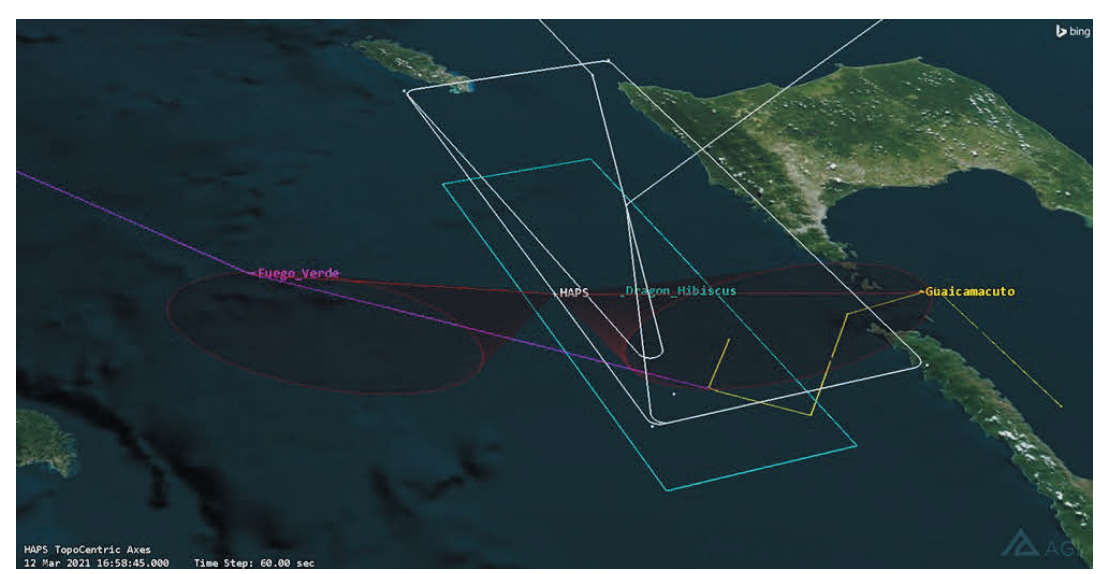

Figure 3: 3-dimensional overview of the operation

Note: Looking from the northwest (Trinidad Island is in the left upper corner). The HAPS uses two sensor footprints (either two separate sensors, or one sensor trained alternately towards the two targets) to observe the terrorist boat (magenta) and the GC-21 (yellow).

Source: Systems ToolKit simulation by the author. 
Closing fast, onboard sensors and lookouts detected that one person on the boat lifted an RPG-7 style anti-armour grenade launcher onto his shoulder. The commander of the patrol vessel identified this as an immediate threat, and the GC-21 opened fire with her $76 \mathrm{~mm}$ cannon. The terrorist boat was destroyed. GC-21 remained on site to search for survivors, bodies or evidence, but none were found. Guaicamacuto left the scene.

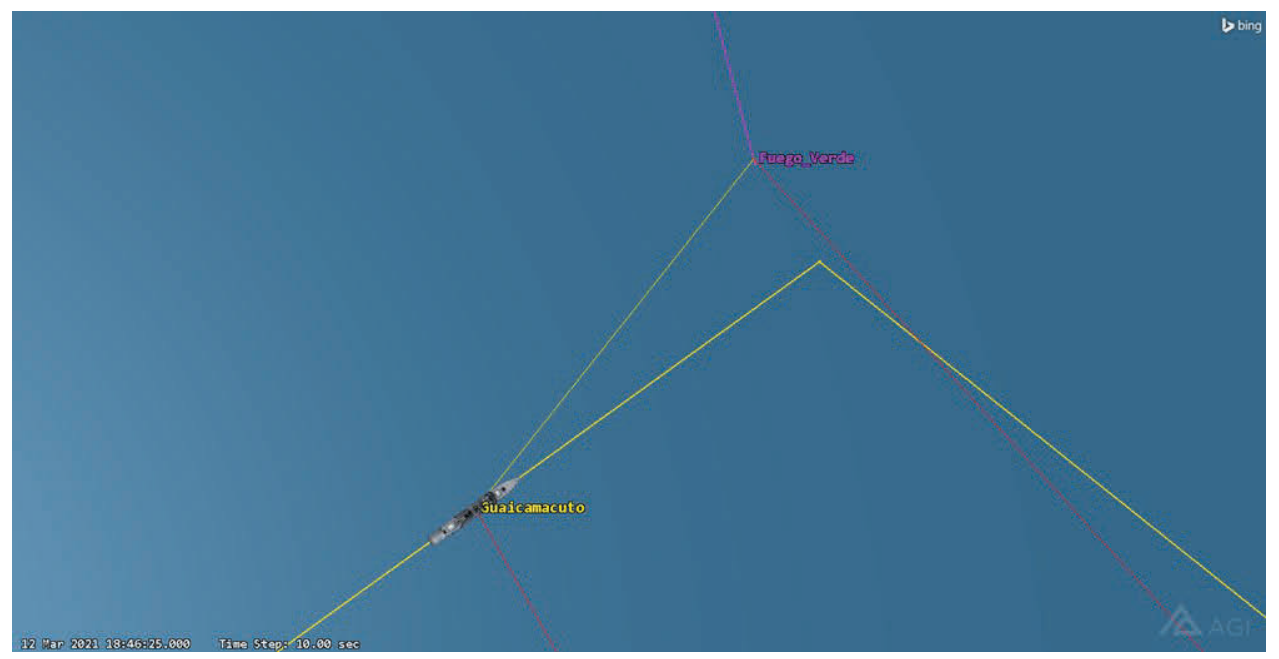

Figure 4: Overhead view of the final engagement

Note: The thin yellow line shows the line of sight/fire from the GC-21 to the terrorist boat. We can see that the rear gun mount (35mm autocannon) was behind the superstructure and could not engage the boat, necessitating the use of the $76 \mathrm{~mm}$ speedfire cannon, even if it was oversized for the target.

Source: Systems ToolKit simulation by the author.

The scenario described above is a work of fiction, but it is certainly representative of the capabilities of HAPS, or pseudo satellites. These are RPAS, flying in the stratosphere, above $20 \mathrm{~km}$ altitude. From here, these aircraft can provide services that are comparable to services of outer space satellites. However, several differences can be found in these services, and even more in the operation of the HAPS, compared not only to satellites, but also to conventional atmospheric aircraft. In my doctoral research, supported by the Co-operative Doctoral Program, I examine these differences and develop applications and procedures for pseudo satellites to operate in an integrated mission support architecture, combined with space satellites.

\section{Introduction to pseudo satellites}

Pseudo satellites are being developed nowadays, and they are a technology for tomorrow. Developments in aero-structural engineering, material science, solar power and battery technology enables their realisation, after decades of theoretical studies. 
High Altitude Platform Stations are aerostatic or aerodynamic atmospheric aircraft, ${ }^{9}$ typically operating between 20 and $30 \mathrm{~km}$ altitude. ${ }^{10}$ Here the atmosphere is relatively calm, compared to the lower-lying troposphere and the jet stream region. This enables effective operation, once the pseudo satellite ascends to operational altitude.

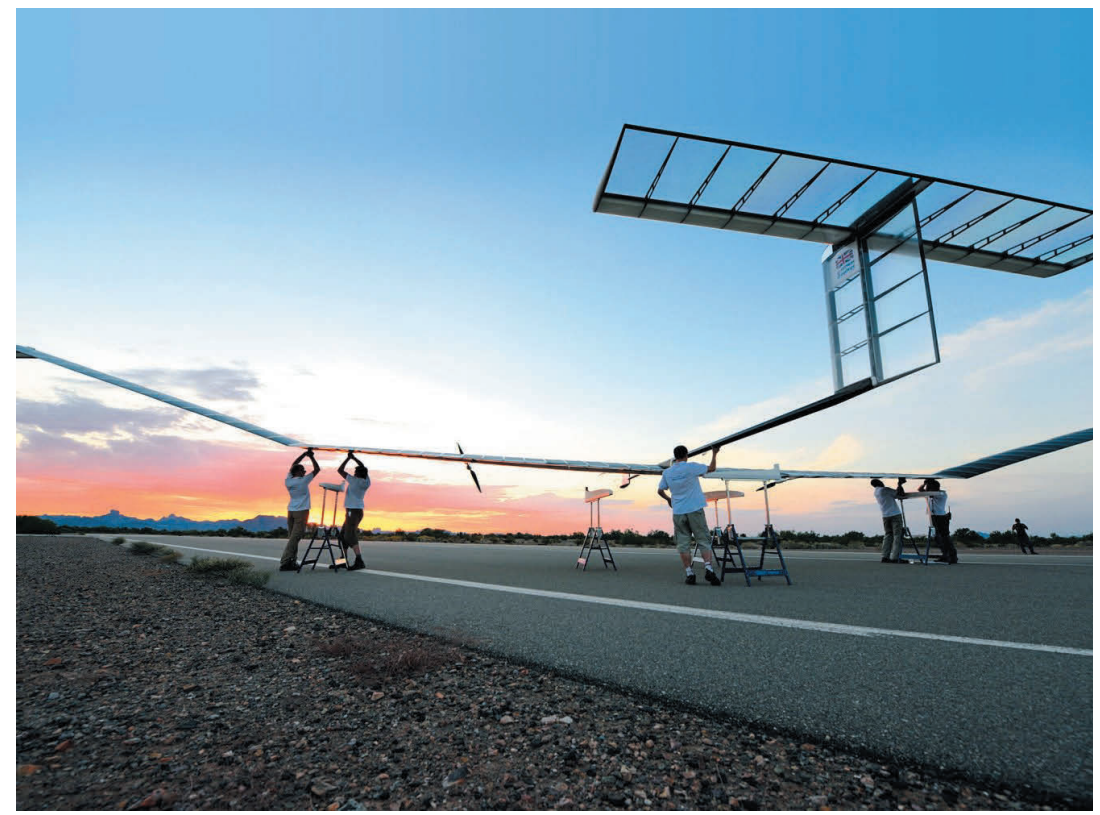

Figure 5: An Airbus Zephyr is being prepared for flight

Source: Airbus.

It must be emphasised that even if these systems are sometimes called pseudo satellites, they are not outer space satellites, and the legal framework they operate under is not governed by the Outer Space Treaty. ${ }^{11}$ Therefore, the expression often used for these systems and the part of the atmosphere they operate, near space ${ }^{12}$ is seriously misleading and should be avoided. To point out graphically the discrepancy of this expression, an Airbus Zephyr HAPS has a "typical operational altitude", ${ }^{13}$ 74,000 feet maximum (22,555 metres), while a MiG-25, an undisputed aerodynamic atmospheric aircraft, in high altitude interceptor

9 Abbas Mohammed et al., 'The Role of High-Altitude Platforms (HAPs) in the Global Wireless Connectivity', Proceedings of the IEEE 99, no 11 (2011).

10 Enis A A Shatri, High Altitude Platforms: Opportunities and Legal Challenges (LAP LAMBERT Academic Publishing, 2019).

11 'Treaty on Principles Governing the Activities of States in the Exploration and Use of Outer Space, Including the Moon and other Celestial Bodies'.

12 Leonard David, 'Sky Trek To The 'Near Space’ Neighborhood', Space.com, 09 November 2005.

13 ATSB Transport Safety Report, 'In-flight break-up involving Airbus Zephyr unmanned aerial vehicle’, 28 September 2020. 
configuration had a service ceiling of $23-24 \mathrm{~km} .{ }^{14}$ Therefore, an atmospheric craft could be looking down on a "near space" craft?

Returning to HAPS, they can be physically realised in three distinct ways, ${ }^{15}$ and this can be used as a basis for categorisation. For all three we can find existing or planned products, and historical examples of development. ${ }^{16}$

The first category is the heavier-than-air aircraft, flying with aerodynamic lift, generated by wings and electrically-powered engines, and those engines provide power for manoeuvring also. The wings are covered with solar panels, and batteries store electricity for the flight during the night. The length of a flight is constrained by the maintenance requirements of the motors and the degradation rate of the batteries.

A prime example of this category is the aforementioned Airbus Zephyr.

The second category is the lighter-than-air airship, either soft (blimp) or semi-rigid, that flies with aerostatic lift, but carries electric motors that drive propellers for horizontal plane manoeuvring. Vertical manoeuvring is done by adjusting the buoyancy of the vehicle. Here the solar panels cover the upper part of the airship body. The body is filled with a lifting gas, typically helium, which is a non-renewable resource, expensive and diffuses through the body material even faster than hydrogen, but it is much safer. With these vehicles, the length of a flight is also constrained by the escape rate of the gas.



Figure 6: Artist's impression of a Stratobus airship in operation

Source: Thales Alenia Space.

14 'Mikoyan-Gurevich MiG-25 Foxbat', s. a.

15 Alejandro Aragón-Zavala et al., High-Altitude Platforms for Wireless Communications (John Wiley \& Sons, Ltd., 2008).

16 J Gavan et al., 'Concepts and Main Applications of High Altitude Platform Radio Relays', The Radio Science Bulletin no 330 (2009). 
The third category is also lighter-than-air, the balloon design. Balloons also fly by aerostatic lift generated by a lifting gas, helium. Vertical manoeuvring is provided by buoyancy adjustment (it should be noted that compared to helium, even air can be used as adjustable ballast weight, so buoyancy control can be done by inflating or deflating an additional air balloon). Since the balloon carries no engines, horizontal plane manoeuvring is provided by carefully adjusting the altitude of the vehicle, and riding the wind that blows in different directions in different altitudes. ${ }^{17}$ Solar electric power is used to supply the payload and the vehicle systems that are very limited compared to the first or second category, since the electric motors are the most significant power consumers.

Station keeping by a balloon cannot be as exact as by motor-driven aircraft, but it is practically accurate enough for effective operations. However, balloons typically do not land at the end of their mission, unlike airships of fixed-wing airplanes that are recoverable. Balloons usually release the lifting gas at the end of their flight and fall to destruction, however, experiments are ongoing to recover them.



Figure 7: Launch of a Raven Industries Aerostar balloon carrying an experimental payload

Source: Raven Industries.

All high altitude platform systems need to ascend above controlled airspace (typically the upper limit of controlled airspace is at flight level 600-660, that is, 60-66,000 feet above mean sea level $^{18}$ ) as fast as practicable, to avoid general air traffic. For this, a specially

17 Salvatore Candido, 'Drifting Efficiently Through the Stratosphere Using Deep Reinforcement Learning', 02 December 2020.

18 FAA, 'Pilot's Handbook of Aeronautical Knowledge, Chapter 15: Airspace'. 
designed airspace needs to be coordinated with the air traffic management service provider or the responsible state authority.

Table 1: Comparison of pseudo satellite technologies

\begin{tabular}{|l|l|l|l|}
\hline & \multicolumn{1}{|c|}{ Fixed wing aircraft } & \multicolumn{1}{c|}{ Airship } & \multicolumn{1}{c|}{ Balloon } \\
\hline Type of lift & Aerodynamic & Aerostatic & Aerostatic \\
\hline Source of lift & $\begin{array}{l}\text { Motor-driven propellers, } \\
\text { airflow over wing profile }\end{array}$ & Helium lifting gas & Helium lifting gas \\
\hline Freedom of manoeuvring & Unlimited & Unlimited & Limited \\
\hline Source of manoeuvring & $\begin{array}{l}\text { Motor-driven propellers, } \\
\text { control surfaces }\end{array}$ & Motor-driven propellers & Wind drift direction \\
\hline Practical useful load & Few kilograms & Few hundred kilograms & Few dozen kilograms \\
\hline
\end{tabular}

Source: Compiled by the author.

However, if the mission area is relatively far from the launch site, the HAPS can stay in the jet stream to get "blown" towards its destination, saving time and energy. In this case, since the jet stream is in controlled airspace, the appropriate flight planning needs to be done.

After reaching the mission area, the HAPS can start station keeping manoeuvres, that is, circling a predefined point, taking the high altitude winds into account; or it can fly on a preplanned patrol pattern (usually an elongated oval shape called racetrack pattern, but the actual patrol route can be different, just as we have seen in the scenario); or it can fly on a route. Daytime the solar panels charge the batteries, and in the case of lighter-than-air vehicles, heat the lifting gas. This energy abundance enables the HAPS to gain altitude, that is, convert the solar energy to potential energy. At night the vehicles descend, that is, they use their potential energy to save on lift (electrical power to drive the motors or lifting gas pressure). ${ }^{19}$ In the example scenario this day-night altitude variation was omitted.

Because of this day-night energy imbalance, we can identify a geographical limitation of HAPS operations: when and where the daytime solar irradiation is insufficient to generate enough energy storage to survive the night, the HAPS cannot operate. For every vehicle and even every flight (because of different payload mass), there is a geographical latitude boundary, limiting the distance from the Equator where the mission is possible. ${ }^{20}$ Relatively close to the Equator, year-round operation is possible, but farther north or south, winter operations might not be viable.

A HAPS flight can last for months, so it is likely that the vehicle needs to be retasked during this time. While the pseudo satellites fly by their onboard autopilots, constant human control is exercised via line-of-sight radio or satellite communications links. The payload data is also downlinked via these connections. At the end of the flight, the HAPS is directed to a suitable landing site for recovery, or in the case of balloons, to a coordinated disposal area.

19 Mou Sun et al., 'Flight Strategy Optimization for High-Altitude Solar-Powered Aircraft Based on Gravity Energy Reserving and Mission Altitude’, MDPI Applied Sciences 10, no 7 (2020), 2243.

20 Lewis Page, 'Airbus Zephyr: The eternal high-altitude surveillance sun-drone’, 18 February 2016. 


\section{Practical applications of High Altitude Platform Systems}

The two system architectures used as a comparison to highlight the importance of pseudo satellite development are well known and established. They provide vital support for numerous human activities, including defence and security. Instead of discussing their technical parameters, these services are used as the basis of the investigation of pseudo satellite applicability.

It must be stated that it is impossible to select just one of these systems to solve all of our current mission support problems. The purpose of the comparative analysis is to highlight where pseudo satellites perform in a superior way, and what are the mission requirements that drive their applications. At the same time, the limitations of the pseudo satellites are also mentioned, again to support system designers and mission planners to build the best architectures for any given operational mission.

We have very limited practical experience operating pseudo satellites. But based on their capabilities, we can say that a typical HAPS lies in-between outer space satellites and the atmospheric high altitude long endurance (HALE) remotely piloted aircraft systems, such as the RQ-4 Global Hawk variants, the Bayraktar Akinci or the WZ-7 Soar Dragon.

The HALE aircraft can carry significantly heavier and more energy-intensive payloads and fly faster. Theoretically, they can operate globally, because after a transport or a ferry flight they can operate from a suitable base airfield, and they can be controlled via satellite links. Since they are powered by a gas turbine engine, they are independent of solar power, and the engine-driven generator can supply enough power the operate practically any payload, even active radar transmitters. Moreover, their day and night flight profile are similar.

At the same time, fuel capacity and engine maintenance limit their flight time to hours, days at most, while a pseudo satellite can fly for weeks or months. HALE RPAS fly lower, and this means they can cover less surface area. These combined means that more aircraft might be needed to execute a given mission, since more is needed to provide area coverage, and they need to be rotated more frequently. This also lowers the mission effectivity, as relatively more time is spent during transit to and from the mission area to the base airfield. More operators, maintainers need to be stationed at the base airfield, and this airfield needs to be located closer to the operational area, potentially increasing the vulnerability of personnel and equipment.

For example, a WZ-7 Soar Dragon can fly for 10 hours at $750 \mathrm{~km} / \mathrm{h} .{ }^{21}$ To reach a target area $1,500 \mathrm{~km}$ away, it needs two hours to fly to and from (practically a little more than that, because of the takeoff and landing manoeuvres), so it can spend somewhat less than 6 hours on station, so more than 4 sorties are necessary to provide constant coverage every 24 hours.

A Bayraktar Akinci can fly for 24 hours, but at half the speed and two-thirds of the altitude, compared to the Soar Dragon. ${ }^{22}$

To illustrate these differences, the coverage of a HAPS flying at $20 \mathrm{~km}$, a Soar Dragon flying at $18 \mathrm{~km}$ and a Bayraktar Akinci flying at $12 \mathrm{~km}$ has been simulated over the

\footnotetext{
${ }^{21}$ Army Recognition, 'Chinese Soar Dragon HALE UAV Unmanned Aerial Vehicle used to spy US Navy USS Antietam’, 04 August 2019.

22 'Bayraktar AKINCI System', s. a.
} 
northeastern Venezuelan coastal area near Trinidad Island. It must be noted that the HALE aircraft are displayed at their respective maximum nominal flight altitude, while the HAPS is set to its practical minimum.

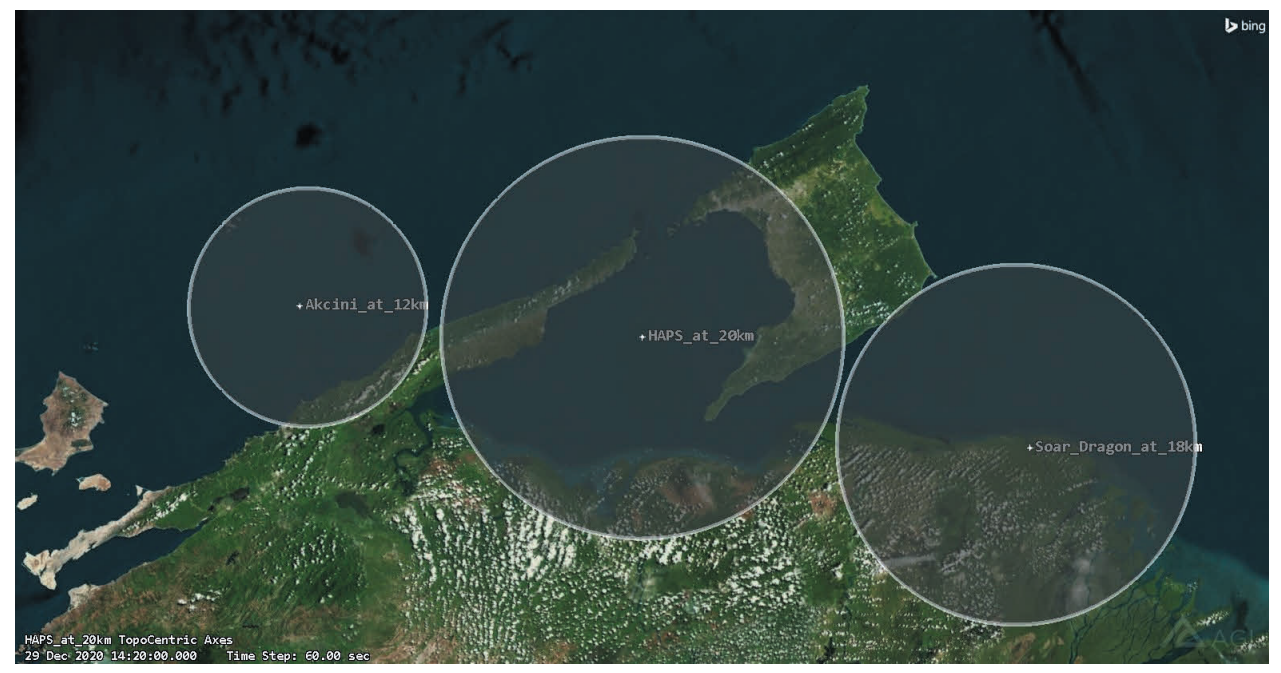

Figure 8: Overhead visualisation of the coverage areas of a HAPS and two HALE RPAS

Source: Systems ToolKit simulation by the author.

To compare the pseudo satellites to outer space, Earth-orbiting satellites, we must first categorise the spacecraft. Based on the potential applications of HAPS, namely remote sensing and telecommunications, we should examine those spacecraft that provide comparable services. These are the Low Earth Orbit (LEO) and the Geostationary/Geosynchronous Earth Orbit (GEO or GSO) satellites.

LEO lies between the altitude where the aerobraking effect becomes practically negligible and the altitude of the lower end of the inner Van Allen belt, about 250-1,300 km. Satellites orbiting here rise above the horizon, ascend on an arc, then start to go down, and finally set beyond the horizon again. ${ }^{23}$ They only spend minutes above the horizon, and, depending on the relative position of the target and the orbital plane, only a relatively short arc can be used for effective observation. At the same time, as the satellite moves on its orbit, it reaches different geographical areas (a polar-orbiting satellite can cover almost the whole globe sooner or later), but it spends only a short time at any given point.

As we have already seen, a HAPS conducting station keeping manoeuvre can spend days, weeks, even months at a predefined target or mission area, keeping it under observation constantly. ${ }^{24}$ When the mission is this, the HAPS beats the space satellite. But a HAPS

${ }^{23}$ For a visual introduction to LEO satellites, the reader is advised to see the graphics at https://horvath.space/ svalbard/

24 Sanja Bauk et al., 'Review of Unmanned Aerial Systems for the Use as Maritime Surveillance Assets', IEEE $202024^{\text {th }}$ International Conference on Information Technology (IT), February 2020. 
cannot move thousands of kilometres within minutes, cannot image geographically distant targets again and again.

Just like spacecraft, HAPS can carry remote sensing payloads. ${ }^{25}$ However, on a typical pseudo satellite, active radars are unlikely to be operated, because the radar transmitter is a very power-intensive device. Visual (be it visible light or infrared) imagers and passive radio receivers (direction finders) can easily be carried, as they fit into the weight and power envelope of the platforms.

The HAPS can cooperate with a satellite-based Earth observation architecture. The space satellites provide early warning of predefined events globally, and when any such trigger event is detected, persistent pseudo satellite overwatch can be activated. After securing the necessary permits and licenses, the HAPS can be transported or can execute a ferry flight to the operational area under control provided via satellite communication. To facilitate effective sensor data download, a suitable ground station can be transported (by a commercial or military cargo aircraft) to the mission area to maintain line-of-sight communications, relieving the satellite communication channels of this burden. At the same time, remotely executed flight control activities can still be conducted via SATCOM, to keep the operators at their existing and optimised workstations, just like space satellites are operated.

If we compare HAPS and geostationary satellites, the service should be telecommunications. The geosynchronous orbit lies approximately 36,000 $\mathrm{km}$ above the Earth, where the orbital period of a satellite equals one rotation of the Earth around its axis. ${ }^{26}$ If the orbit has zero inclination, that is, the orbital plane lies in the plane of the Equator, the satellite seems stationary for an observer on the Earth. The satellite always covers the same area, theoretically, 44\% of the surface of the Earth. Extreme northern and southern areas close to the poles lie behind the Earth curvature, so no service can be provided there from a geostationary satellite. However, within the coverage area, the satellites provide highquality, constant, persistent service. ${ }^{27}$

These satellites, however, are huge (typically 3-5 metric tons), very expensive, and the manufacturing and launching capabilities are constrained to a few countries and commercial entities. The design lifetime of such a satellite is 12-15 years, and with careful operation, this can be extended by a few years (which, since the price of such a satellite is counted in hundred million Euros, is very desirable by the operators). This means that the designer has to plan forward 20-23 years into the future - or an operator needs to work with technology designed more than two decades earlier.

The distance between the satellite and the ground station communicating with it is approximately 40,000 km. Double that to reach another ground station via the satellite, and one can find that telecommunication protocols used in terrestrial systems are not designed to

25 Sanja Bauk et al., 'Advantages and Disadvantages of Some Unmanned Aerial Vehicles Deployed in Maritime Surveillance’, Universitat Politècnica de Catalunya. Departament de Ciència i Enginyeria Nàutiques, September 2020.

26 Clarke, Arthur C, 'Extra-terrestrial relays’, Wireless World, October 1945.

27 For a visual introduction to the geosynchronous orbit, the reader is advised to visit https://horvath.space/ comconf-2019-material/ 
handle such propagation delay, and even voice communication can be uncomfortable for the users because of the delay.

Pseudo satellites cannot cover such a huge area, but can provide focused service for a selected and pre-determined mission area. Interestingly, we see that even in space satellite communication technology, the coverage area is divided into several smaller "cells" or "subbeams" to optimise the service for the user requirements (this technology is usually called $\left.\mathrm{HTS}^{28}\right)$.

The big geographical coverage area of a telecommunication satellite, if not segmented into sub-beams by HTS, is a serious vulnerability (electronic warfare actions, either jamming or reception, is possible via an unauthorised station installed anywhere within the coverage area) and a waste of spectrum resources. The relatively focused service coverage of the HAPS inherently overcomes these disadvantages.

Moreover, the HAPS can be recovered and serviced between flights, so the transponder payload can be adapted to the mission and can always be state-of-the-art. This way the HAPS can always provide an ultimately mission-optimised service, which can constantly evolve with the advance of technology and user requirements.

The highest service value can be realised, again, by the cooperation of the two system architectures. The pseudo satellite provides service between the users within its coverage area, that is tailored to the operation supported. Only long-distance, out-of-area links need to be carried over satellites.

\section{Potential applications of High Altitude Platform Systems to support security and defence operations relevant to South America and South Europe}

Almost all South American countries (with the exception of the Plurinational State of Bolivia and the Republic of Paraguay) have sea coastlines. A sea coast comes with a maritime border to guard, an economical zone to oversee and administer, a maritime search and rescue area to be prepared to be deployed to. Moreover, Chile and Argentina also have significant Antarctic territories.

The same can be said about South European countries, within the Mediterranean area, but in the case of the Kingdom of Spain and the Portuguese Republic, a significant section of the Atlantic Ocean also comes under their responsibility, and for the French Republic, even the Indian Ocean is important in addition to the aforementioned areas.

Covering these areas with conventional maritime patrol aircraft is very personnel- and equipment-intensive. Most states operate legacy turboprop aircraft for this mission, only the Airbus C-295 MPA and a few modernised P-3 Orion versions can be considered up-to-date. The Embraer KC-390 could be a candidate platform for a maritime patrol aircraft, but as the developer country, Brazil, has already two MPA types in its inventory (and operates the cargo version of the C-295, on which the MPA is based), such a move is unlikely.

28 Gonzalo de Dios, High-Throughput Satellites Technology Trends (Lima, Peru: ITU Regional Radiocommunication Seminar 2017 for the Americas [RRS-17-Americas], 2017). 
The temporary nature of aircraft presence (or the necessity of an impractical number of aircraft to provide permanent presence) is a serious limitation of aerial support. ${ }^{29}$ Comparing this limitation to the vast ocean and ground area to be covered, we see that when a mission requires persistent coverage and high resolution imagery or fast and adaptive telecommunication coverage, pseudo satellites are a logical choice, especially when operated jointly by the several countries.

Constant, persistent surveillance by Earth-orbiting satellites would require dozens of spacecraft, that would spend most of their lifetime above areas far away. While this can also be considered a valuable service, a HAPS is better optimised for such a task.

Piracy and smuggling, an important law enforcement problem in the Caribbean, more confined to coastal waters, needs even more focused attention and faster reaction, which is particularly fitting for a pseudo satellite operation.

Just like that, surveillance of the large and sparsely inhabited inland areas, like the Amazonas Basin, the Mato Grosso or Patagonia are important for conservation, law enforcement and emergency management reasons. HAPS can provide overwatch of these areas also, and when surface forces need to be deployed, the surveillance and telecommunication capabilities can be readily directed to support them.

The situation is practically the same in case of the Mediterranean, where the illegal transportation, smuggling of displaced persons is important to detect because of humanitarian and law enforcement reasons.

In the Indian Ocean, again, piracy needs the attention of maritime surveillance operators, and Réunion or Mayotte, French overseas departments, could be very good operational bases for pseudo satellites escorting ships transiting the Arabian Sea, the Mozambique Channel and the central Indian Ocean.

\section{Conclusion}

High Altitude Platform Systems, or pseudo satellites, are an emerging technology. And they can safely be called disruptive also. These remotely piloted aerial vehicles fly in the stratosphere, undisturbed by the weather influencing flight operations in the lower atmosphere, and are capable of covering a selected operational area for weeks or months on, unlike LEO space satellites that move away within minutes, and do not return (unless operated in greater numbers) for hours.

HAPS close the gap between aircraft and space operations, and can provide intelligence, surveillance, reconnaissance or telecommunication support to military, border guard, inland or maritime law enforcement, emergency response operations, or any state or commercial activity typically supported nowadays by those two platforms.

In this article, based on an imaginary scenario, I introduced the technology behind these stratospheric stations, and compared the services provided by them to both lower atmospheric

29 Michael Spencer, Pseudosatellites Disrupting Air Power Impermanence (Canberra: Air Power Development Centre, 2019). 
aircraft and outer space satellites. We have seen that their services, be it remote sensing or telecommunication, can most effectively be utilised by operating them combined.

Finally, I have shown examples, relevant to the nations of South America and South Europe, how HAPS could be deployed to support their relevant defence and security activities.

The illustrations for this article were generated with the Analytical Graphics Systems ToolKit $^{30}$ software. This industry standard multidomain mission simulator is used, for example, by the NATO Space Center, and also the Hungarian Defence Forces Modernization Institute.

This article is based on my presentation at the South America, South Europe International Conference organised by the Doctorates' Council of the Ludovika - University of Public Service and the Department of International Security Studies of the Faculty of Military Science and Officer Training.

More visuals, including pictures and videos can be found at the website https://horvath. space/haps-scenario.

\section{References}

Aragón-Zavala, Alejandro, José Luis Cuevas-Ruíz and José Antonio Delgado-Penín, High-Altitude Platforms for Wireless Communications. John Wiley \& Sons, Ltd., 2008. Online: https://doi. org/10.1002/9780470997437

Army Recognition, 'Chinese Soar Dragon HALE UAV Unmanned Aerial Vehicle used to spy US Navy USS Antietam’, 04 August 2019. Online: www.armyrecognition.com/ august_2019_global_defense_security_army_news_industry/chinese_soar_dragon_hale_ uav_unmanned_aerial_vehicle_used_to_spy_us_navy_uss_antietam.html

ATSB Transport Safety Report, 'In-flight break-up involving Airbus Zephyr unmanned aerial vehicle’, 28 September 2020. Online: www.atsb.gov.au/media/5778702/ao-2019-056_final. pdf

Bauk, Sanja, Nexhat Kapidani, Žarko Lukšić, Filipe Rodrigues and Luís Sousa, 'Review of Unmanned Aerial Systems for the Use as Maritime Surveillance Assets'. IEEE $202024^{\text {th }}$ International Conference on Information Technology (IT), February 2020. Online: https://doi. org/10.1109/IT48810.2020.9070718

Bauk, Sanja, Nexhat Kapidani, Luis Sousa, Žarko Lukšić and Agim Spuža, ‘Advantages and Disadvantages of Some Unmanned Aerial Vehicles Deployed in Maritime Surveillance’. Universitat Politècnica de Catalunya. Departament de Ciència i Enginyeria Nàutiques, September 2020. Online: https://upcommons.upc.edu/handle/2117/329709

'Bayraktar AKINCI System’, s. a. Online: https://baykardefence.com/uav-14.html Candido, Salvatore, 'Drifting Efficiently Through the Stratosphere Using Deep Reinforcement Learning’, 02 December 2020. Online: https://blog.x.company/drifting-efficiently-throughthe-stratosphere-using-deep-reinforcement-learning-c38723ee2e90

30 Systems ToolKit, online: www.agi.com/products/stk 
Clarke, Arthur C, ‘Extra-terrestrial relays’. Wireless World, October 1945. Online: http:// clarkeinstitute.org/wp-content/uploads/2010/04/ClarkeWirelessWorldArticle.pdf

David, Leonard, 'Sky Trek To The 'Near Space' Neighborhood'. Space.com, 09 November 2005. Online: www.space.com/1761-sky-trek-space-neighborhood.html

De Dios, Gonzalo, High-Throughput Satellites Technology Trends. Lima, Peru: ITU Regional Radiocommunication Seminar 2017 for the Americas (RRS-17-Americas), 2017. Online: www.itu.int/en/ITU-R/seminars/rrs/RRS-17-Americas/Documents/Forum/2_Intelsat\%20 Gonzalo\%20de\%20Dios.pdf

FAA, 'Pilot’s Handbook of Aeronautical Knowledge, Chapter 15: Airspace’. Online: www.faa.gov/ regulations_policies/handbooks_manuals/aviation/phak/media/17_phak_ch15.pdf

Gavan, J, S Tapuchi and D Grace, 'Concepts and Main Applications of High Altitude Platform Radio Relays’. The Radio Science Bulletin no 330 (2009). Online: https://ieeexplore.ieee.org/ stamp/stamp.jsp?arnumber=7909716

'Introduction to Remotely Piloted Aircraft Systems (RPAS)'. Skybrary, s. a. Online: www. skybrary.aero/index.php/Introduction_to_Remotely_Piloted_Aircraft_Systems_(RPAS)

Kurt, Gunes Karabulut, Mohammad G Khoshkholgh, Safwan Alfattani, Ahmed Ibrahim, Tasneem S J Darwish, Md Sahabul Alam, Halim Yanikomeroglu and Abbas Yongacoglu, 'A Vision and Framework for the High Altitude Platform Station (HAPS) Networks of the Future'. IEEE Communications Surveys \& Tutorials 23, no 2 (2021). Online: https://doi.org/10.1109/ COMST.2021.3066905

Mohammed, Abbas, Asad Mehmood, Fotini-Niovi Pavlidou and Mihael Mohorcic, 'The Role of High-Altitude Platforms (HAPs) in the Global Wireless Connectivity'. Proceedings of the IEEE 99, no 11 (2011). Online: https://doi.org/10.1109/JPROC.2011.2159690

'Mikoyan-Gurevich MiG-25 Foxbat', s. a. Online: www.fighter-planes.com/info/mig25_foxbat. htm

Page, Lewis, ‘Airbus Zephyr: The eternal high-altitude surveillance sun-drone’, 18 February 2016. Online: https://arstechnica.com/information-technology/2016/02/the-amazing-eternalsun-drone-will-the-zephyr-shine-or-burn/

Shatri, Enis A A, High Altitude Platforms: Opportunities and Legal Challenges. LAP LAMBERT Academic Publishing, 2019.

Spencer, Michael, Pseudosatellites Disrupting Air Power Impermanence. Canberra: Air Power Development Centre, 2019. Online: https://airpower.airforce.gov.au/sites/default/ files/2021-03/AP37-Pseudosattelites-Disrupting-Air-Power-Impermanence.pdf

Sun, Mou, Xinzhe Ji, Kangwen Sun and Ming Zhu, 'Flight Strategy Optimization for HighAltitude Solar-Powered Aircraft Based on Gravity Energy Reserving and Mission Altitude’. MDPI Applied Sciences 10, no 7 (2020), 2243. Online: https://doi.org/10.3390/app10072243

'Treaty on Principles Governing the Activities of States in the Exploration and Use of Outer Space, Including the Moon and other Celestial Bodies'. Online: www.unoosa.org/pdf/gares/ ARES_21_2222E.pdf

Tzŭ, Sun, The Art of War. Trans. by Lionel Giles, MA, 1910. Online: www.gutenberg.org/ files/132/132-h/132-h.htm

Widiawan, Anggoro K and Rahim Tafazolli, 'High Altitude Platform Station (HAPS): A Review of New Infrastructure Development for Future Wireless Communications'. Wireless Personal Communications 42 (2007), 387-404. Online: https://doi.org/10.1007/s11277-006-9184-9 